\title{
Penguins and their noisy world
}

\author{
THIERRY AUBIN \\ NAMC CNRS UMR 8620, Université Paris-Sud, Bât. 446, 91405 Orsay Cedex, France \\ Manuscript received on January 15, 2004; accepted for publication on February 5, 2004.
}

\begin{abstract}
Penguins identify their mate or chick by an acoustic signal, the display call. This identification is realized in a particularly constraining environment: the noisy world of a colony of thousands of birds. To fully understand how birds solve this problem of communication, we have done observations, acoustic analysis, propagation and playback experiments with 6 species of penguins studied in the field. According to our results, it appears that penguins use a particularly efficient "anti-confusion", and "anti-noise" coding system, allowing a quick identification and localization of individuals on the move in a noisy crowd.
\end{abstract}

Key words: communication in noise, sound localization, vocal recognition, penguins.

\section{INTRODUCTION}

In penguins, the call an adult produces when seeking its chick or its partner among thousands of birds is transmitted in a context involving the noise generated by the colony and the screening effect of the bodies. Both these factors drastically reduce the signal-to-noise ratio and mask the signal by a background noise with similar spectral and temporal characteristics. In addition, in some penguin species, there is no nest: the brooder carries the egg or the small chick on the feet. This absence of visual landmarks enhances the difficulty of individuals to locate the right bird on the move in a noisy crowd. Faced with this difficult problem penguins nevertheless succeed. How do they manage this? To answer to this question, we have conducted field studies involving signal analysis, propagation and playback experiments dealing with the identification calls of 6 species of penguins.

\section{MATERIALS AND METHODS}

We have studied in Australia, Antarctica and subantarctic islands 2 species without a nest, the Emperor (EP)Aptenodytes forsteri and the King (KP)A. patagonicus Penguins and 4 species with a nest, the Adélie (AP) Pygoscelis adeliae, the Gentoo (GP) $P$. papua, the Macaroni (MP) Eudyptes chrysolophus and the Little Blue (BP) Eudyptula minor Penguins.

To fully understand an acoustic communication, it is necessary to study each step of the process. This implies: 1) studying the coding process, by analyzing the structure of the acoustic signal; 2) evaluating the modifications of the signal during propagation; 3) performing experiments with acoustic lures, i.e. using modified signals broadcast to the animal while observing the behavioral responses in order to emphasize the key information-bearing parameters.

\section{RESULTS}

\section{The Display Call}

In penguins, mates or parents and chicks can recognize each other using only an acoustic signal, the 


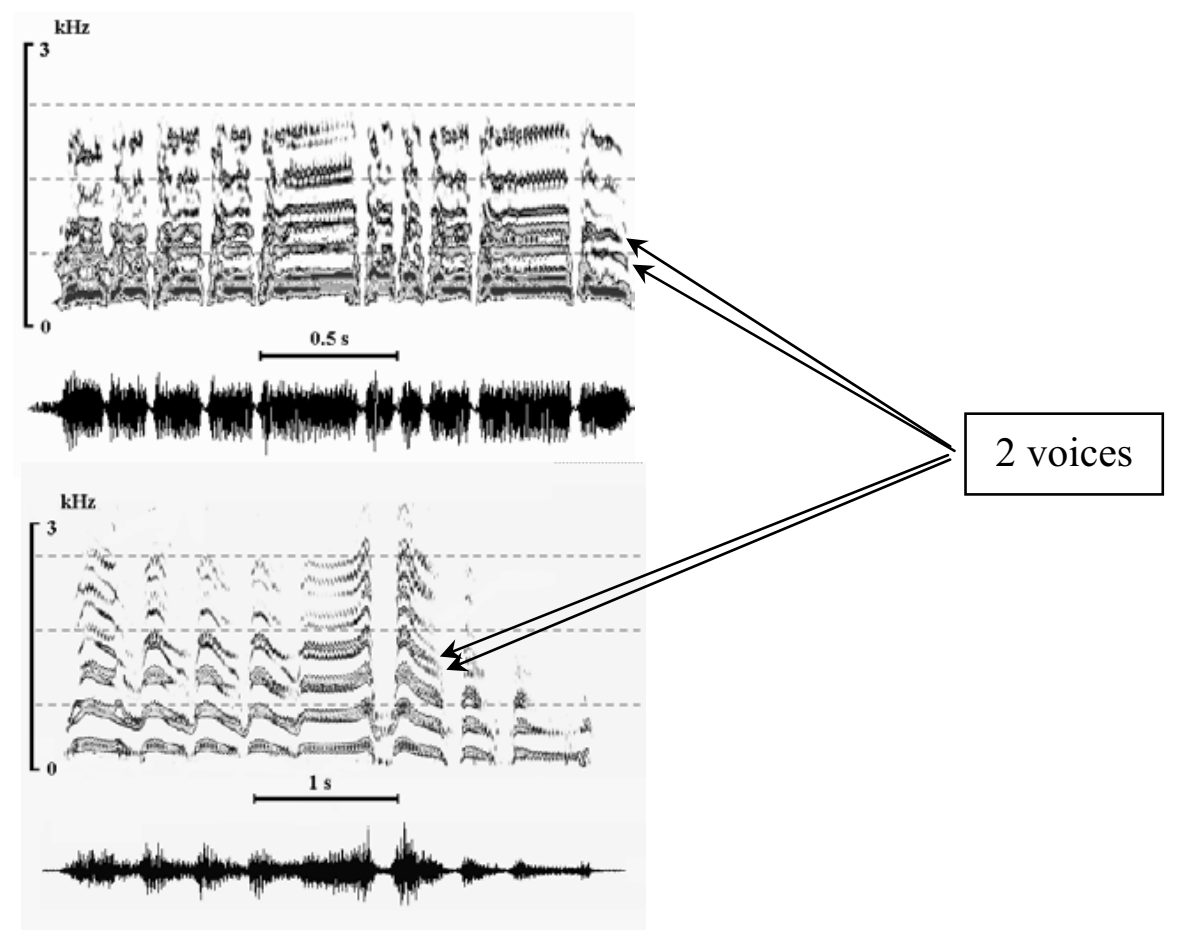

Fig. 1 - The "two voices" phenomenon in the calls of the Emperor Penguin (top) and of the King Penguin (bottom), evidenced as simultaneous and harmonically unrelated frequencies.

display call. It consists of a series of more or less similar sound components (the syllables) separated by strong amplitude declines. The syllable is a complex sound with harmonic series from $250 \mathrm{~Hz}$ to up to $5000 \mathrm{~Hz}$. Among the 17 species of penguins, only two - the EP and the KP (Fig. 1) - use the "twovoices" (Brémond et al. 1990, Aubin et al. 2000). The "two-voices" phenomenon refers to the bird's ability to produce two sounds, either simultaneously or independently, from their syrinx.

\section{THE INDIVIDUAL STEREOTYPY}

PCA and Coefficient of Variation analysis, in the temporal and frequency domains, reveal that an individual signature can be found in the display calls of all the species of penguin studied (Robisson et al. 1989, Jouventin and Aubin 2000, Aubin and Jouventin 2002a): for each individual, the structure of the signal is stereotyped (Fig. 2).

\section{The Behavioral Strategies}

To limit the time they take to identify the mate or chick, penguins use particular searching strategies. Although colonies often number thousands of individuals, an adult coming from the sea does not have to locate its partner or chick among all of these individuals. In fact, the search is limited to particular "rendez-vous" sites: the nest or, for KPs, the previous feeding areas memorized by the birds (Lengagne et al. 1999c). To optimize the "active space" of their signal, penguins also adopt particular signaling and hearing postures that limit the absorption caused by the screening effect of bodies of the birds gathered in dense flocks (Lengagne et al. 1999a).

\section{The “Cocktail Party”’ Effect}

The call is transmitted in a context involving the noise generated by the colony (about $75 \mathrm{~dB}_{\mathrm{SPL}}$ ) and the screening effect of the bodies. According to our 

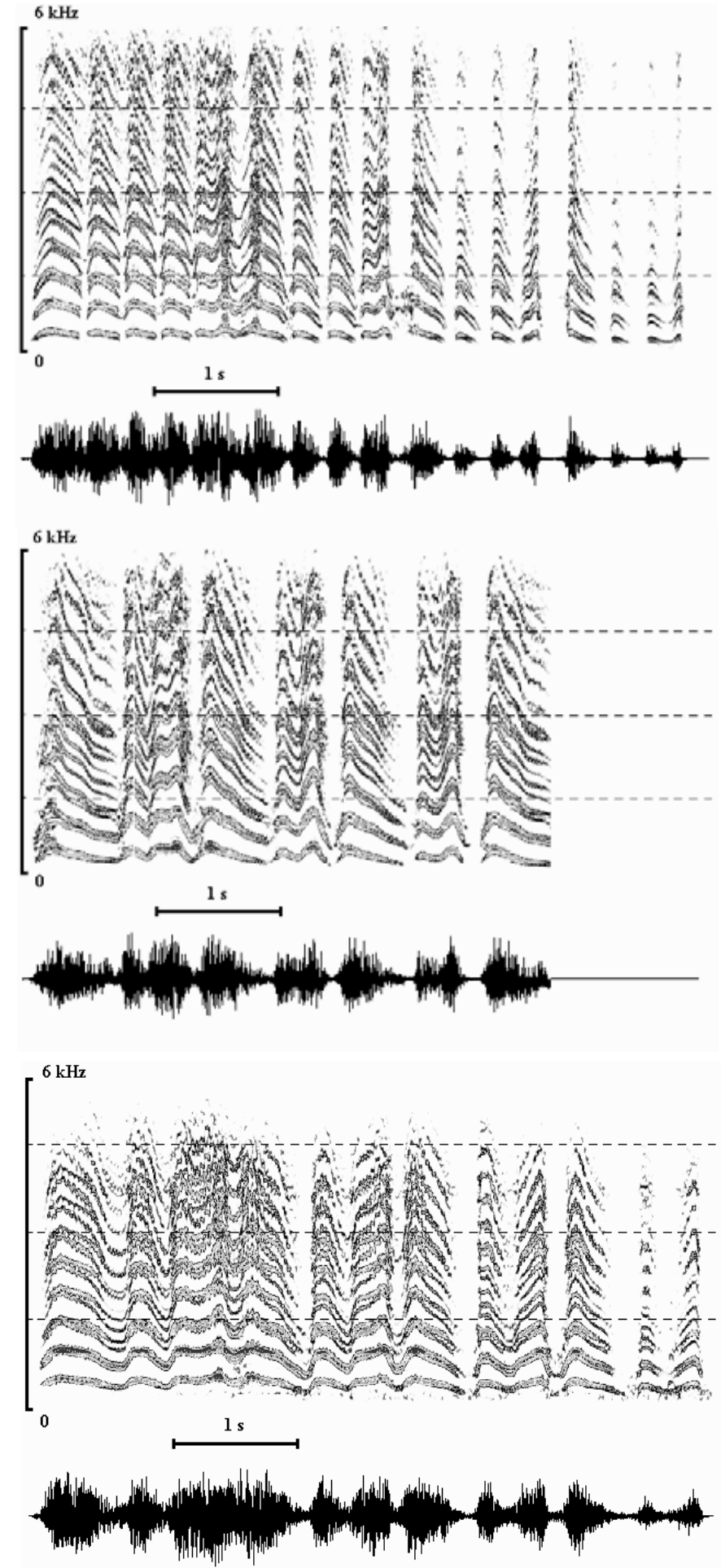

Fig. 2 - Sonograms of the calls of 3 individuals of King Penguin. Calls are different from one individual to another and stereotyped for each individual. 
experiments (Aubin and Mathevon 1995, Aubin and Jouventin 1998), after $13 \mathrm{~m}$ of propagation, the amplitude gaps that separate syllables and the peaks of frequencies tend to disappear into the background noise. Nevertheless, in natural conditions, birds are able to detect a familiar song at a longer distance $(16 \mathrm{~m})$. To estimate the minimal discrimination threshold in a jamming situation, a series of mixed signals was broadcast to individuals. The familiar call was combined with extraneous calls with different emergence levels, measured as signal-to-noise ratios. Our experiments with KPs indicate that birds detect a familiar call, even when its intensity is $6 \mathrm{~dB}$ below that of the noise of simultaneous calls produced by other adults (Aubin and Jouventin 1998). This capacity to extract the familiar signal from signals of other conspecifics is termed "cocktail-party effect' in speech intelligibility tests.

\section{The Vocal Signature}

Studying the discrimination of the adult call by the chick or the mate we have used play-back experiments modifying acoustic parameters to analyze the coding-decoding mechanisms of nesting (Jouventin and Aubin 2000, 2002, Searby et al. 2004) and nonnesting penguins (Robisson et al. 1993, Jouventin et al. 1999, Aubin et al. 2000, Lengagne et al. 2000).

To extract a signal from the noise, penguins use two adaptive processes: analysis of call frequency bands for nesting penguins or analysis of frequency/time modulations for penguins without a nest. In addition, we have demonstrated that the penguins without nests use in fact a twin coding system since the beats generated by the interaction of the two voices convey also information about individual identity (Aubin et al. 2000, Lengagne et al. 2001).

The frequency analysis used by nesting penguins is adequate for the easier problem of the individual recognition in nesting birds, whereas the complex acoustic code of the non-nesting penguins is an adaptation to their extreme acoustic and breeding conditions.

\section{THE REDUNDANCY OF INFORMATION}

The broadcast of one syllable of a familiar call against a normal background noise elicits weak responses from the bird tested (Aubin and Jouventin 2002b). Although it contains the whole identity code, one syllable alone is not sufficient to reliably convey the information, given the ambient noise of the colony.

As predicted by information theory, birds must repeat the information to ensure an efficient communication in a noisy channel. This is verified in windy conditions: when the wind speed increases, this leads to a diminution of the signal-to-noise ratio and birds try to maintain the volume of information sent by increasing the number of syllables per call (Lengagne et al. 1999b). Thus, penguins apply the mathematical theory of information!

\section{The Signal Localization}

The syllabic organization of the call and the harmonic structure of the syllable apparently do not contribute to individual recognition but these structures are not useless. We have shown by playback experiments (Aubin and Jouventin 2002b) that these structures help the bird to better localize the signal of the emitter and thus facilitate the meeting between individuals.

\section{CONCLUSION}

According to our results, it appears that penguins adopt two kinds of strategies to optimize identification in background noise: 1) behavioral strategies: use of meeting places, adaptation of signaling postures and searching methods; 2) acoustical strategies: use of a well-matched code for identification of the signal in the noise, of a redundant and locatable acoustic structure. Thus, the particularly efficient acoustic system of penguins allows recognition and localization of individuals within a very constraining environment: a colony of thousands of birds, with a huge background noise and a lack of visual cues. 


\section{ACKNOWLEDGMENTS}

Logistic supports were provided by the Institut Paul-Emile Victor. Many thanks to Christophe Hildebrant, Pierre Jouventin, Jacques Lauga, Thierry Lengagne and Patrice Robisson for their participation to the study.

\section{RESUMO}

Os pingüins identificam seu parceiro ou seu filhote através de um sinal acústico, o grito de exibição. Esta identificação está realizada num ambiente particularmente exigente: o mundo barulhento de uma colônia de milhares de aves. Para entender totalmente como essas aves resolvem este problema de comunicação, realizamos observações, análises acústicas e experiências de propagação e de "play-back" com 6 espécies de pingüins estudados no campo. Segundo nossos resultados, parece que os pingüins usam um sistema de codificação “anti-confusão" e "anti-barulho" particularmente eficiente, permitindo uma rápida identificação e localização dos indivíduos em movimento numa multidão barulhenta.

Palavras-chave: comunicação no barulho, localização de som, reconhecimento vocal, pingüins.

\section{REFERENCES}

Aubin T And Jouventin P. 1998. Cocktail-party effect in King Penguin colonies. Proc R Soc Lond B265: 1665-1673.

Aubin T And Jouventin P. 2002a. How to identify vocally a kin in a crowd? The penguin model. Adv Study Behav 31: 243-277.

Aubin T AND Jouventin P. 2002b. Localisation of an acoustic signal in a noisy environment: the display call of the King Penguin. J Exp Biol 205: 3793-3798.

Aubin T and Mathevon N. 1995. Adaptation to severe conditions of propagation: long-distance distress calls and courtship calls of a colonial seabird. Bioacoustics 6: 153-161.

Aubin T, Jouventin P and Hildebrand C. 2000. Penguins use the two-voice system to recognise each other. Proc R Soc Lond B267: 1081-1087.

Brémond JC, Aubin T, Mbu Nyamsi R and Robisson P. 1990. The song of the Emperor Penguin: research of parameters likely to be used for individual recognition. CR Acad Sci 311: 31-35.

Jouventin P And Aubin T. 2000. Acoustic convergence in the calls of two nocturnal burrowing seabirds. Experiments with a penguin and a shearwater. Ibis 142 : 645-656.

Jouventin P And Aubin T. 2002. Acoustic systems are adapted to breeding ecologies: individual recognition in nesting penguins. Anim Behav 64: 747-757.

Jouventin P, Aubin T and Lengagne T. 1999. Finding a parent in a King Penguin colony: the acoustic system of individual recognition. Anim Behav 57: 1175-1183.

Lengagne T, Aubin T, Jouventin P And Lauga L. 1999a. Acoustic communication in a King Penguin colony: importance of bird location within the colony and of the body position of the listener. Polar Biol 21: $262-268$.

Lengagne T, Aubin T, Lauga J and Jouventin P. 1999b. How do King Penguins apply the Mathematical Theory of Information to communicate in windy conditions? Proc R Soc Lond B266: 1623-1628.

Lengagne T, Jouventin P And Aubin T. 1999c. Finding one's mate in a King Penguin colony: efficiency of acoustic communication. Behaviour 136: 833846.

Lengagne T, Aubin T, Jouventin P and Lauga J. 2000. Perceptual salience of individually distinctive features in the calls of adult King Penguins. J Acoust Soc Am 107: 508-516.

Lengagne T, Lauga J And Aubin T. 2001. Intrasyllabic acoustic signatures used by the King Penguin in parent-chick recognition: an experimental approach. J Exp Biol 204: 663-672.

Robisson P, Aubin T And BRÉmond JC. 1989. Individual recognition by voice in the Emperor Penguin: respective parts of the temporal pattern and the sound structure of the courtship song. CR Acad Sci 309: 383-388.

Robisson P, Aubin T And BRÉmond JC. 1993. Individuality in the voice of the Emperor Penguin Aptenodytes forsteri: adaptation to a noisy environment. Ethology 94: 279-290.

Searby A, Jouventin P And Aubin T. 2004. Acoustic recognition in Macaroni Penguins: an original signature system. Anim Behav (in press). 